\title{
Postnatal condition of the second twin in respect to mode of delivery, chorionicity and type of fetal growth
}

\author{
Jerzy S. Florjański ${ }^{1, A-F}$, Wojciech Homola ${ }^{1, A-D, F}$, Tomasz Fuchs ${ }^{1, B, E, F}$, Agata Pawłosek 2,B,E,F, Mariusz Kasperski2,B,E,F \\ ${ }^{1}$ II Department of Gynecology and Obstetrics, Faculty of Medicine, Wroclaw Medical University, Poland \\ ${ }^{2}$ Clinic of Gynecology and Obstetrics, Jan Mikulicz-Radecki University Teaching Hospital, Wrocław, Poland \\ A - research concept and design; B - collection and/or assembly of data; C - data analysis and interpretation; \\ $D$ - writing the article; $E$ - critical revision of the article; $F$ - final approval of the article
}

\section{Jerzy Florjański \\ E-mail: jerzyflorjanski@wp.pl \\ Funding sources \\ None declared \\ Conflict of interest \\ None declared}

Address for correspondence

Received on December 21, 2017

Reviewed on April 17, 2018

Accepted on May 5, 2018

Published online on November 22, 2018

Cite as

Florjański JS, Homola W, Fuchs T, Pawłosek A, Kasperski M. Postnatal condition of the second twin in respect to mode of delivery, chorionicity and type of fetal growth. Adv Clin Exp Med. 2019;28(2):237-242. doi:10.17219/acem/90765

DOI

$10.17219 /$ acem/90765

\section{Copyright}

Copyright by Author(s)

This is an article distributed under the terms of the

Creative Commons Attribution Non-Commercial License

(http://creativecommons.org/licenses/by-nc-nd/4.0/)

\begin{abstract}
Background. The increased use of assisted reproductive techniques (ART) contributes to the increased rate of twin pregnancies, which are burdened with a higher risk of complications. Factors that affect the condition of the second twin are understudied.
\end{abstract}

Objectives. The objective of this study was to assess the impact of the delivery mode, chorionicity, amnionicity, and the type of fetal growth on the postnatal condition of the second twin.

Material and methods. The study included data from 475 pregnant women with twin pregnancies. Maternal age, parity, chorionicity, amnionicity, type of fetal growth, mode of delivery, gestational weeks at delivery, Apgar score, and umbilical arterial blood pH were retrospectively analyzed. Data normality was checked with the Kolmogorov-Smirnov test. The paired Wilcoxon signed-rank test and $x^{2}$ test were used for comparisons between groups. To check predictive value of the analyzed variables multiple linear regression was used.

Results. The mean maternal age was 29.22 (standard deviation (SD) \pm 5.19 ) years. The maternal age and gestational age at delivery did not differ significantly between women who delivered by cesarean section (CS) and vaginal delivery (VD). In the second twin, the Apgar score and values of arterial umbilical blood pH were lower in infants delivered by VD than in those delivered by CS ( $6.30 \pm 2.83$ and $7.30 \pm 0.12$; $p=0.0209$ and $7.26 \pm 0.12$ and $7.30 \pm 0.11 ; p=0.0236$, respectively). In monochorionic diamniotic twins with asymmetric growth, the second twin achieved significantly lower outcome than the first twin. Vaginal delivery was a predictive factor for a lower Apgar score and lower values of umbilical arterial blood pH in second twins, while not in first twins. Symmetrical fetal growth of twins was a predictive factor for better postnatal condition for both twins.

Conclusions. In twin pregnancies, VD, but not CS, is associated with increased risk of worse postnatal condition of the second twin. In monochorionic diamniotic pregnancies complicated by growth discordance, CS seems to be a reasonable mode of delivery.

Key words: twin pregnancy, mode of delivery, chorionicity, type of twin growth, postnatal condition of the second twin 


\section{Introduction}

Difficulties in obtaining offspring and delayed child bearing are associated with the increased use of assisted reproductive techniques (ART). This trend translates into the occurrence of multiple births. Historically, multiple birth rates began to decline in the 1950s, with the minimum rates in the 1970 s, and then, after the introduction and popularization of ART and pharmacological ovulation stimulation, they began to rise since 1998. As the ART become more advanced and tailored, the incidence of triplets and higher order pregnancies decreases, which contributes to a further increase in twin rate. ${ }^{1,2}$ Multiple gestations are considered a potential complication of ART. ${ }^{3}$

Births in twin pregnancies pose an increased risk of complications to the second fetus. During vaginal delivery (VD) after birth of the first twin, the uterus contracts rapidly, and the uterine contractile function weakens or disappears, which may significantly prolong the $2^{\text {nd }}$ stage of the labor of the second twin. Also, a rapid change in hemodynamic conditions occurs and may negatively affect the condition of the second twin. Therefore, $10-20 \%$ of the second twins may require a cesarean section (CS). ${ }^{4,5}$

The incidence of $t$ win deliveries remains on a similar level in developed countries across the world. In the USA, the rate of twin deliveries was 33.5 per 1,000 total births in $2015 .^{2}$ Multifetal pregnancies are associated with a higher risk of perinatal complications compared to singleton pregnancies, both conceived naturally and after ART. ${ }^{6,7}$ Some authors reported that factors such as chorionicity, mode of delivery, type of fetal growth (discordant or symmetric), and birth mass worsen perinatal outcomes and increase the rate of neonatal complications in the second twin compared to the first one. ${ }^{8-10}$ On the other hand, broad trials have been conducted which did not show the superiority of CS vs VD in terms of complications in neonates, especially in the absence of risk factors and when the first twin is in the cephalic presentation. ${ }^{11-13}$ The authors of the meta-analysis from 2011, which included nearly 40,000 twin pairs, concluded that, in the absence of risk factors, VD is safer than CS for the first twin but for the second twin, the mode of delivery had no effect on perinatal outcome. ${ }^{14}$ In light of controversies and inconsistent reports on the impact of selected parameters on the condition of the second twin in the literature, we decided to perform an analysis of the postnatal condition of the fetuses from twin pregnancies among the population of Wrocław, Poland.

The aim of the study was to assess the influence of the delivery mode, chorionicity, and type of fetal growth on the postnatal condition of twins, as measured with an Apgar score and umbilical arterial blood $\mathrm{pH}$ in neonates.

\section{Material and methods}

The study included data from 475 pregnant women with twin pregnancies, who delivered in the II Department of Gynecology and Obstetrics, Wroclaw Medical University, Poland. The data for retrospective analysis included maternal age, parity, chorionicity, type of fetal growth, mode of delivery, gestational weeks at delivery, Apgar score, and umbilical arterial blood $\mathrm{pH}$. Discordance was defined as $18 \%$ intertwin birthweight difference, as reports from the literature suggest that perinatal mortality increases with birthweight discordance exceeding $18 \%$ in twins without twin-twin transfusion syndrome (TTTS). ${ }^{15}$ Subjects with pregnancies complicated by genetic and developmental defects in twins or TTTS, and those with a history of intrauterine death of one of the twins were excluded from the study. The study was approved by the Bioethics Committee at the Wroclaw Medical University.

Data was collected in the Excel spreadsheet (MS Office 2010; Microsoft Corp., Redmond, USA) and statistically analyzed with the $\mathrm{R}$ Project for Statistical Computing v. 3.4.1 (www.r-project.org). Summary values were given as a mean ( \pm standard deviation $-\mathrm{SD}$ ) or median (interquartile rage - IQR). The normality of the data was checked with the Kolmogorov-Smirnov test. The paired Wilcoxon signed-rank test was used for comparisons between fetuses and the unpaired test was used for other comparisons. To compare categorical variables, the $\chi^{2}$ test was used. To check the predictive value of the analyzed variables, a multiple linear regression was used. The p-value $<0.05$ was considered statistically significant.

\section{Results}

Data from 475 pregnant women with twin pregnancies was analyzed. Out of these 475 women, 313 (65\%) were dichorionic diamniotic (DCDA), the remaining ones were monochorionic diamniotic (MCDA) and 1 was monochorionic monoamniotic (MCMA). Due to the fact that there was only 1 case of the MCMA pregnancy, this case was excluded from the analysis. The mean maternal age was 29.22 (SD \pm 5.19 ) years (range: $18-47$ years). Differences in the maternal age and gestational weeks at delivery between pregnancies ended by CS and VD were insignificant. Primigravidae constituted the majority of the study group - 270 (57\%), and additionally, they significantly more frequently delivered by CS. The second twins delivered vaginally achieved a significantly lower Apgar score and had a significantly lower umbilical arterial blood $\mathrm{pH}$ than those delivered by CS. The comparison of clinical characteristics regarding delivery mode is presented in Table 1.

A paired comparison of the postnatal condition as measured with Apgar score and values of umbilical arterial blood $\mathrm{pH}$ by chorionicity and fetal growth type is presented in Table 2. It can be seen that a twin born second achieved 
Table 1. Clinical characteristics of the study group

\begin{tabular}{|c|c|c|c|c|}
\hline Variable & $\begin{array}{c}\text { Total } \\
(n=474)\end{array}$ & $\begin{array}{l}\text { Vaginal delivery } \\
\qquad(n=105)\end{array}$ & $\begin{array}{l}\text { Cesarean section } \\
\qquad(n=369)\end{array}$ & $p$-value \\
\hline Maternal age [years], mean $\pm \mathrm{SD}$ & $29.21 \pm 5.19$ & $29.07 \pm 5.71$ & $29.25 \pm 5.04$ & 0.7468 \\
\hline Gestational age [weeks], mean \pm SD & $35.41 \pm 3.44$ & $35.22 \pm 4.77$ & $35.46 \pm 2.95$ & 0.0779 \\
\hline $\begin{array}{l}\text { Parity, n (\%) } \\
\text { primiparae } \\
\text { multiparae }\end{array}$ & $\begin{array}{l}270(56.96) \\
204(43.04)\end{array}$ & $\begin{array}{l}41(15.18) \\
64(31.37)\end{array}$ & $\begin{array}{l}229(84.82) \\
140(68.63)\end{array}$ & $<0.001$ \\
\hline $\begin{array}{l}\text { Growth type, n (\%) } \\
\text { symmetrical twins } \\
\text { discordant twins }\end{array}$ & $\begin{array}{l}308(64.98) \\
166(35.02)\end{array}$ & $\begin{array}{l}62(20.07) \\
43(25.90)\end{array}$ & $\begin{array}{l}246(79.87) \\
123(74.10)\end{array}$ & 0.149 \\
\hline $\begin{array}{l}\text { Chorionicity/amnionicity, n (\%) } \\
\text { DCDA } \\
\text { MCDA }\end{array}$ & $\begin{array}{l}311(65.61) \\
163(34.39)\end{array}$ & $\begin{array}{l}74(23.79) \\
31(19.02)\end{array}$ & $\begin{array}{l}237(76.21) \\
132(80.98)\end{array}$ & 0.234 \\
\hline Apgar score - first twin, median (IQR) & $8(6-9)$ & $7(6-9)$ & $8(6-9)$ & 0.3703 \\
\hline Apgar score - second twin, median (IQR) & $7(6-9)$ & $7(6-9)$ & $8(6-9)$ & 0.0206 \\
\hline $\mathrm{pH}$ - first twin, mean $\pm \mathrm{SD}$ & $7.29 \pm 0.12$ & $7.28 \pm 0.12$ & $7.30 \pm 0.12$ & 0.3108 \\
\hline $\mathrm{pH}-$ second twin, mean $\pm \mathrm{SD}$ & $7.29 \pm 0.11$ & $7.26 \pm 0.12$ & $7.30 \pm 0.11$ & 0.0237 \\
\hline
\end{tabular}

DCDA - dichorionic diamniotic; IQR - interquartile range; MCDA - monochorionic diamniotic; SD - standard deviation; p-values in bold denote statistical significance.

significantly worse outcome in comparison to the one born first, but only in the case of monochorionic diamniotic pregnancies with asymmetric growth delivered vaginally. In the case of CS, those differences were insignificant. Differences between twins with other types of growth and chorionicity/amnionicity were insignificant.

Vaginal delivery was a significant predictive factor for a lower Apgar score and a lower value of umbilical arterial blood $\mathrm{pH}$ after adjustment for gestational age, maternal age, parity, type of growth, and chorionicity/amnionicity only for the second twin. For the first twin, the delivery mode did not play a significant predictive role. Symmetric growth was a positive predictive factor for better perinatal condition for both twins. Also, gestational age was a significant predictive factor for a higher Apgar score and a higher umbilical arterial blood $\mathrm{pH}$ value. With every additional gestational week, the $\mathrm{pH}$ increased by 0.0180 for the first twin and by 0.0177 for the second twin. With every additional gestational week, the Apgar score increased by 0.3875 for the first twin and by 0.3480 for the second twin. Regression coefficients are presented in Table 3.

\section{Discussion}

Our study identifies VD as a risk factor for a worse perinatal status in the second twins, when factors such as twin discordance, preterm delivery and monochorionicity coexist. In the present study, the Apgar score and values of umbilical arterial blood $\mathrm{pH}$ were lower in the second twins delivered by VD than in those delivered by CS. In monochorionic diamniotic twins with discordant growth, the second twin achieved significantly lower outcome than the first twin. Additionally, VD was a negative predictive factor for worse perinatal outcome in the group of the second twins, while not in the group of the first ones.

Twin pregnancy is burdened with a higher risk of adverse perinatal outcomes and of maternal complications than a singleton pregnancy. ${ }^{16,17}$ Thus, obstetricians search

Table 2. Comparison of Apgar score and umbilical arterial blood pH between the first and the second twin regarding type of growth and mode of delivery

\begin{tabular}{|c|c|c|c|c|c|c|c|c|}
\hline \multirow{2}{*}{ Variable } & \multirow{2}{*}{$\begin{array}{l}\text { Delivery } \\
\text { mode }\end{array}$} & \multirow{2}{*}{$\mathrm{n}(\%)$} & \multicolumn{2}{|c|}{ Apgar score; median (IQR) } & \multirow{2}{*}{$p$-value } & \multicolumn{2}{|c|}{ pH; mean (SD) } & \multirow{2}{*}{$\mathrm{p}$-value } \\
\hline & & & first twin & second twin & & first twin & second twin & \\
\hline \multirow{2}{*}{$\begin{array}{l}\text { DCDA } \\
\text { concordant }\end{array}$} & VD & $49(21)$ & $8(6-9)$ & $7(6-9)$ & 0.3564 & $7.28(0.12)$ & $7.28(0.10)$ & 0.5934 \\
\hline & $\mathrm{CS}$ & $184(79)$ & $8(7-9)$ & $8(7-9)$ & 0.5381 & $7.31(0.11)$ & $7.32(0.10)$ & 0.8218 \\
\hline \multirow{2}{*}{$\begin{array}{l}\text { DCDA } \\
\text { discordant }\end{array}$} & VD & $25(32)$ & $7(5-8)$ & $8(5-9)$ & 0.7195 & $7.28(0.11)$ & $7.29(0.11)$ & 0.1806 \\
\hline & CS & $53(68)$ & $7(6-8)$ & $7(5-8)$ & 0.7923 & $7.27(0.10)$ & $7.27(0.10)$ & 0.9183 \\
\hline \multirow{2}{*}{$\begin{array}{l}\text { MCDA } \\
\text { concordant }\end{array}$} & VD & $13(17)$ & $7(7-8)$ & $7(4-9)$ & 0.3586 & $7.28(0.11)$ & $7.26(0.13)$ & 0.5291 \\
\hline & $\mathrm{CS}$ & $62(83)$ & $8(7-9)$ & $8(6-9)$ & 0.1287 & $7.33(0.12)$ & $7.32(0.10)$ & 0.5587 \\
\hline \multirow{2}{*}{$\begin{array}{l}\text { MCDA } \\
\text { discordant }\end{array}$} & VD & $18(20)$ & $7(3.4-8.0)$ & $5.5(1.25-7.00)$ & 0.0334 & $7.28(0.13)$ & $7.18(0.17)$ & 0.0274 \\
\hline & CS & $70(80)$ & $7(4.25-8.00)$ & $6(4-8)$ & 0.5109 & $7.25(0.13)$ & $7.23(0.13)$ & 0.3583 \\
\hline \multicolumn{2}{|l|}{ Total VD } & 105 & $7(6-9)$ & $7(5-8)$ & 0.1034 & $7.28(0.12)$ & $7.26(0.13)$ & 0.3438 \\
\hline \multicolumn{2}{|l|}{ Total CS } & 369 & $8(6-9)$ & $8(6-9)$ & 0.5591 & $7.30(0.12)$ & $7.30(0.11)$ & 0.5593 \\
\hline \multicolumn{2}{|c|}{ Total concordant } & 308 & $8(7-9)$ & $8(7-9)$ & 0.4217 & $7.31(0.11)$ & $7.31(0.10)$ & 0.6276 \\
\hline \multicolumn{2}{|c|}{ Total discordant } & 166 & $7(5-8)$ & $7(4.25-8.00)$ & 0.2442 & $7.26(0.12)$ & $7.25(0.13)$ & 0.2959 \\
\hline \multicolumn{2}{|l|}{ Total } & 474 & $8(6-9)$ & $7(6-9)$ & 0.1904 & $7.29(0.12)$ & $7.29(0.11)$ & 0.3156 \\
\hline
\end{tabular}

CS - cesarean section; IQR - interquartile range; DCDA - dichorionic diamniotic; MCDA - monochorionic diamniotic; VD - vaginal delivery;

p-values in bold denote statistical significance. 
Table 3. Multiple linear regression model

\begin{tabular}{|l|c|c|c|c|}
\multirow{2}{*}{ Intercept/variable } & Estimate & $p$-value & Estimate & $p$-value \\
\cline { 2 - 6 } & \multicolumn{2}{|c|}{ first twin } & \multicolumn{2}{|c|}{ second twin } \\
\hline Intercept - pH & 6.6305 & $<0.0001$ & 6.6385 & $<0.0001$ \\
\hline Gestational weeks & 0.0180 & $<0.0001$ & 0.0177 & $<0.0001$ \\
\hline Concordant growth & 0.0344 & 0.0004 & 0.0445 & $<0.0001$ \\
\hline Vaginal delivery & - & - & -0.0320 & 0.0027 \\
\hline Intercept - Apgar & -7.3666 & $<0.0001$ & -6.0940 & $<0.0001$ \\
\hline Gestational weeks & 0.3875 & $<0.0001$ & 0.3480 & $<0.0001$ \\
\hline Concordant growth & 1.0271 & $<0.0001$ & 1.2131 & $<0.0001$ \\
\hline Vaginal delivery & - & - & -0.5876 & 0.0104 \\
\hline
\end{tabular}

$\mathrm{pH}$ - arterial umbilical blood $\mathrm{pH}$.

for optimal planning and timing of the delivery to increase the safety of both the fetuses and the mother. Some reports from the literature suggest that outcomes achieved after CS and VD are comparable in normal pregnancies without risk factors. A randomized trial conducted by Barrett et al. compared the 2 modes of planned delivery. The study group included twins with cephalic presentation and an estimated fetal weight between 1,500 g and 4,000 g. Monoamniotic twins and pregnancies with any complications that could negatively affect the course of labor were excluded. As a result, the difference in fetal/neonatal death or serious neonatal morbidity between the study groups was insignificant. ${ }^{11}$ A 2-year observation of children conducted within the framework of the Twin Birth Study, which aimed to evaluate the incidence of death or neurodevelopmental delay, revealed no benefit of planned CS when compared to VD in uncomplicated twin pregnancies between 32 and 38 weeks of gestation. ${ }^{18}$ Nevertheless, there are also reports on large populations of normal twins at or after 36 weeks of gestation, which show that planned CS reduces the risk of perinatal death of the second twin in comparison with attempting a VD. ${ }^{19} \mathrm{On}$ the other hand, a recent study showed that in women with dichorionic diamniotic twins, attempted VD was followed by a spontaneous VD of both twins in only $46 \%$ of cases. The later required instrumental VD and an emergency CS. ${ }^{4}$ Additionally, a VD in twin pregnancies increases maternal morbidity, especially in terms of increased rate of postpartum hemorrhage. ${ }^{13,20}$

Some authors assessed selected risk factors that may potentially affect the postnatal condition of twins or increase the risk of neonatal morbidity for both twins. Zipori et al. reported a higher percentage of respiratory distress syndrome (RDS) and transient tachypnea of the newborn (TTN) in twins delivered by VD in comparison to those delivered by CS. ${ }^{21}$ Shinwell et al. evaluated a group of twins with a birthweight lower than 1,500 g. They found that the risk for RDS and death was higher for the second twin than for the first twin, but was independent of the mode of the delivery. ${ }^{10}$ Hartley and Hitti showed that the highest rate of combined poor short-term perinatal outcomes occurred in fetuses delivered by operative VD. ${ }^{22}$ These reports are in line with the results of the present study which revealed that in the group of twin with risk factors, VD contributed to the worsening of the second fetus condition. Regression analysis from our study highlights that prematurity may worsen the condition of both fetuses, while asymmetric growth affects especially the condition of the second fetus.

Newborn babies are routinely assessed with an Apgar score. A low score at $1 \mathrm{~min}$ and $5 \mathrm{~min}$ indicates that a newborn requires medical attention. It is also a predictor for neonatal survival. A score of 8 and above was considered normal in our study. In the present study, the mean value of the Apgar score was $6.30 \pm 2.83$ with a median of 7 in the group of second twins delivered by VD and was significantly lower than the value obtained in babies delivered by CS $-7.06 \pm 2.37$ with the median of 8 . Multiple regression analysis showed that VD was a negative predictive factor for a lower Apgar score in the group of second twins. Similar outcomes were reported by other researchers. Hartley and Hitti reported that the relative risk for low 5-minute Apgar score was 1.4 (95\% confidence interval $(\mathrm{CI})=1.1-1.8)$ for VD or CS during labor in comparison with CS without labor. ${ }^{22}$ Jhaveri and Nadkarni found that odds ratio (OR) for an Apgar score of 7 or lower was 3.385 (95\% CI $=1.2099-9.4684, \mathrm{p}=0.02$ ) in the vaginal group compared to the CS group. ${ }^{23}$ And recently, Ylilehto et al. showed that VD affected the condition of the second twin without differences in the rate of serious neonatal morbidity and as a result, the second VD twins more often had 5 -minute Apgar scores $<7(\mathrm{p}=0.002)$ than second twins delivered by $\mathrm{CS}^{24}$

Umbilical arterial blood $\mathrm{pH}$ is measured in infants at high risk for neonatal asphyxia after delivery. This parameter is strongly associated with neonatal mortality and morbidity; thus, obstetricians try to undertake possible actions early enough to prevent a drop in umbilical arterial blood $\mathrm{pH} .{ }^{25}$ In the present study, the mean umbilical arterial blood $\mathrm{pH}$ value was $7.26 \pm 0.12$ in the group of second twins delivered vaginally in comparison to $7.30 \pm 0.11$ in second twins delivered by CS. This difference was statistically significant. Vaginal delivery was a significant predictive factor for low $\mathrm{pH}$ value only in the group of second twins. Our findings are consistent with reports from the literature. Sato et al. reported that umbilical arterial blood $\mathrm{pH}$ was significantly lower in the case of VD in comparison to CS (7.26 \pm 0.009 vs $7.30 \pm 0.006 ; p=0.0003)$ in second twins, but not in the first twins. Additionally, in the second twins the percentage of umbilical arterial blood pH below 7.20 was significantly higher in VD than this in CS group (20\% vs $4 \% ; \mathrm{p}=0.0001) .{ }^{8}$ Ylilehto et al. showed that umbilical arterial blood $\mathrm{pH}<7.05$ appeared more often in VD second twins than in second CS twins $(\mathrm{p}=0.003) .{ }^{24}$ The team headed by Leung draws attention to the effect of delivery interval between twins and the duration of the $2^{\text {nd }}$ stage of labor. According to their outcomes, prolonged delivery interval 
deteriorates blood parameters. Changes in the umbilical cord blood gas status become significant when the interval between births exceeds $30 \mathrm{~min} .{ }^{26}$ Also, as the duration of the $2^{\text {nd }}$ stage of labor is prolonged, the umbilical cord blood gas status deteriorated in both twins, but to a greater degree in the second twin than in the first twin. ${ }^{27}$

Growth discordance between twins is considered an important predictor of worse perinatal outcomes, but its definition may vary. In the present study, growth discordance was defined as 18\% difference in birthweight between twins without TTTS. ${ }^{15}$ Our analysis confirmed that discordant growth is a significant predictive factor for a lower Apgar score and a lower umbilical arterial blood $\mathrm{pH}$ for both twins. In addition, second twins from discordant monochorionic diamniotic pregnancies ended by a VD achieved significantly worse perinatal outcomes that those of the first twin. Data from the literature indicates that the greater difference in estimated twin mass is, the greater neonatal morbidity and mortality. ${ }^{28,29}$ Thus, in the case of a big difference in estimated twin mass (over $30 \%$ ) detected in ultrasound examination, we preferred CS as a delivery mode. This led to difficulties in assessing the impact of the delivery mode on perinatal outcomes.

In the literature, a comparison of the status between smaller and larger fetuses is more common than between the first and second twin. There are some reports documenting decreased well-being of the second twins. However, there are also several reports regarding the postnatal status of the second twins.

Kontopoulos et al. showed that in pregnancies complicated by discordance greater than $40 \%$, the mode of delivery had no effect on perinatal outcomes, but in the case of discordance between $20 \%$ and $40 \%$, delivery by CS was associated with a lower rate of neonatal mortality. ${ }^{30}$ Canpolat et al. found that the second twin had an increased risk of $\mathrm{RDS}(\mathrm{OR}=1.3 ; 95 \% \mathrm{CI}=0.6-2.4)$ after adjustment for birthweight. ${ }^{31}$ Usta et al. found that in pregnancies in which the second twin is more than $250 \mathrm{~g}$ larger than the first twin, no differences in the incidence of intraventricular hemorrhage, seizures, sepsis, and neonatal death between twins were noted, except for the a lower median Apgar score in the second twin. ${ }^{32}$ It is worth noting that growth discordance often coexists with head-to-abdominal circumference asymmetry or intrauterine growth restriction (IUGR) in one of the twins, or with being small for gestational age (SGA), which can further deteriorate perinatal outcomes. ${ }^{33}$

\section{Conclusions}

In twin pregnancies, VD is associated with an increased risk of a worse postnatal condition of the second twin in comparison with delivery by CS. In monochorionic diamniotic pregnancies complicated by growth discordance, CS seems to be a reasonable mode of delivery.

\section{References}

1. Collins J. Global epidemiology of multiple birth. Reprod Biomed Online. 2007;15(Suppl 3):45-52.

2. Martin JA, Hamilton BE, Osterman MJ, Driscoll AK, Mathews TJ. Births: Final data for 2015. Natl Vital Stat Rep. 2017;66(1):1.

3. Huang JY, Rosenwaks Z. Assisted reproductive techniques. Methods Mol Biol. 2014;1154:171-231.

4. Rzyska E, Ajay B, Chandraharan E. Safety of vaginal delivery among dichorionic diamniotic twins over 10 years in a UK teaching hospital. Int J Gynaecol Obstet. 2017;136(1):98-101.

5. Kong CW, To WWK. The predicting factors and outcomes of caesarean section of the second twin. J Obstet Gynaecol. 2017;37(6):709-713.

6. Qin JB, Wang H, Sheng X, Xie Q, Gao S. Assisted reproductive technology and risk of adverse obstetric outcomes in dichorionic twin pregnancies: A systematic review and meta-analysis. Fertil Steril. 2016;105(5):1180-1192.

7. Rao A, Sairam S, Shehata H. Obstetric complications of twin pregnancies. Best Pract Res Clin Obstet Gynaecol. 2004;18(6):557-576.

8. Sato Y, Emoto I, Maruyama S, Taga A, Fujii T. Twin vaginal delivery is associated with lower umbilical arterial blood $\mathrm{pH}$ of the second twin and less intrapartum blood loss. J Matern Fetal Neonatal Med. 2016;29(19):3067-3071.

9. Kosińska-Kaczyńska K, Szymusik I, Bomba-Opoń D, et al. Perinatal outcome according to chorionicity in twins: A Polish multicenter study. Ginekol Pol. 2016;87(5):384-389.

10. Shinwell ES, Blickstein I, Lusky A, Reichman B. Effect of birth order on neonatal morbidity and mortality among very low birthweight twins: A population based study. Arch Dis Child Fetal Neonatal Ed. 2004;89(2):F145-F148.

11. Barrett JF, Hannah ME, Hutton EK, et al; Twin Birth Study Collaborative Group. A randomized trial of planned cesarean or vaginal delivery for twin pregnancy. N Engl J Med. 2013;369(14):1295-1305.

12. Schmitz T, Prunet C, Azria E, et al; JUmeaux MODe d'Accouchement (JUMODA) Study Group and the Groupe de Recherche en Obstétrique et Gynécologie (GROG). Association between planned cesarean delivery and neonatal mortality and morbidity in twin pregnancies. Obstet Gynecol. 2017;129(6):986-995.

13. Sadeh-Mestechkin D, Daykan Y, Bustan M, Markovitch O, Shechter-Maor G, Biron-Shental T. Trial of vaginal delivery for twins: Is it safe? A single center experience. J Matern Fetal Neonatal Med. 2018;31(15):1967-1971.

14. Rossi AC, Mullin PM, Chmait RH. Neonatal outcomes of twins according to birth order, presentation and mode of delivery: A systematic review and meta-analysis. BJOG. 2011;118(5):523-532.

15. Breathnach FM, McAuliffe FM, Geary M, et al; Perinatal Ireland Research Consortium. Definition of intertwin birth weight discordance. Obstet Gynecol. 2011;118(1):94-103.

16. Kiely JL. The epidemiology of perinatal mortality in multiple births. Bull N Y Acad Med. 1990;66(6):618-637.

17. Barrett JF. Twin delivery: Method, timing and conduct. Best Pract Res Clin Obstet Gynaecol. 2014;28(2):327-338.

18. Asztalos EV, Hannah ME, Hutton EK, et al. Twin Birth Study: 2-year neurodevelopmental follow-up of the randomized trial of planned cesarean or planned vaginal delivery for twin pregnancy. Am J Obstet Gynecol. 2016;214:371.

19. Smith GC, Shah I, White IR, Pell JP, Dobbie R. Mode of delivery and the risk of delivery-related perinatal death among twins at term: A retrospective cohort study of 8073 births. BJOG. 2005;112(8):1139-1144.

20. Easter SR, Robinson JN, Lieberman E, Carusi D. Association of intended route of delivery and maternal morbidity in twin pregnancy. Obstet Gynecol. 2017;129(2):305-310.

21. Zipori Y, Smolkin T, Makhoul IR, Weissman A, Blazer S, Drugan A. Optimizing outcome of twins by routine cesarean section beyond 37 weeks. Am J Perinatol. 2011;28(1):51-56.

22. Hartley RS, Hitti J. Please exit safely: Maternal and twin pair neonatal outcomes according to delivery mode when twin $A$ is vertex. J Matern Fetal Neonatal Med. 2017;30(1):54-59.

23. Jhaveri RR, Nadkarni TK. Perinatal outcome of second twin with respect to mode of delivery: An observational study. J Clin Diagn Res. 2016;10(12):QC26-QC28.

24. Ylilehto $\mathrm{E}$, Palomäki $\mathrm{O}$, Huhtala $\mathrm{H}$, Uotila J. Term twin birth: Impact of mode of delivery on outcome. Acta Obstet Gynecol Scand. 2017;96(5):589-596. 
25. Malin GL, Morris RK, Khan KS. Strength of association between umbilical cord $\mathrm{pH}$ and perinatal and long term outcomes: Systematic review and meta-analysis. BMJ. 2010;340:c1471.

26. Leung TY, Tam WH, Leung TN, Lok IH, Lau TK. Effect of twin-to-twin delivery interval on umbilical cord blood gas in the second twins. BJOG. 2002;109(1):63-67.

27. Leung TY, Lok IH, Tam WH, Leung TN, Lau TK. Deterioration in cord blood gas status during the second stage of labour is more rapid in the second twin than in the first twin. BJOG. 2004;111(6):546-549.

28. Hollier LM, McIntire DD, Leveno KJ. Outcome of twin pregnancies according to intrapair birth weight differences. Obstet Gynecol. 1999; 94(6):1006-1010.

29. Demissie K, Ananth CV, Martin J, Hanley ML, MacDorman MF, Rhoads GG. Fetal and neonatal mortality among twin gestations in the United States: The role of intrapair birth weight discordance. Obstet Gynecol. 2002;100(3):474-480.
30. Kontopoulos EV, Ananth CV, Smulian JC, Vintzileos AM. The influence of mode of delivery on twin neonatal mortality in the US: Variance by birth weight discordance. Am J Obstet Gynecol. 2005;192(1): 252-256.

31. Canpolat FE, Yurdakök M, Korkmaz A, Yigit S, Tekinalp G. Birthweight discordance in twins and the risk of being heavier for respiratory distress syndrome. Twin Res Hum Genet. 2006;9(5):659-663.

32. Usta IM, Nassar AH, Abu Musa AA, Awwad JT, Yunis KA, Seoud MA. Perinatal outcome of vaginally delivered twin gestations with a larger twin B. J Perinatol. 2003;23(5):409-413.

33. Dashe JS, McIntire DD, Santos-Ramos R, Leveno KJ. Impact of headto-abdominal circumference asymmetry on outcomes in growth-discordant twins. Am J Obstet Gynecol. 2000;183(5):1082-1087. 